\title{
Orthographic Errors Committed by Sophomore Students: A Linguistic Analysis
}

\section{Franklin ThambiJose.S}

\author{
Sultan Idris Education University, Malaysia
}

Email: thambijoshs@gmail.com

Doi:10.5901/mjss.2014.v5n23p2439

\section{Abstract}

The process by which people learn a second language can be termed as Second language learning. It can also be said that, 'a language learned by people apart from their native language or mother tongue'. Sometimes it becomes a must situation in multilingual societies. In many countries English is learned as second language due to various reasons. Students when they learn English as Second language commit different types of errors. One such error is orthographic error. Writing of words without proper spelling can be termed as orthographic errors. It is committed inadvertently. Since English has so many odd spellings, everyone makes the occasional orthographic error. In a learning situation, this type of error is committed by students when they write. This article tries to explain orthographic errors committed by college level sophomore students of Eritrea Institute of Technology, Asmara, North East Africa, while they write in English. Furthermore, the types of errors committed and remedies are also given.

Keywords: Language; Orthographic; Errors; Sophomore; Remedy.

\section{Introduction}

Orthography is a correct way of writing a particular language. The term orthography came from Greek language which means 'correct way of writing'. The conventional spelling system of a language is orthography. It is the standardised procedure of a writing system which includes spelling, pronunciation, word break, emphasis, etc. Punctuation, work break, and emphasis are not a big problem for the learners. But spelling is a problem for all learners and that is the main issue in orthography. In English, spelling plays an important role in writing process. It is not easy to write without any spelling mistakes for a non-native speaker (second language learner) of English because a second language learner must use 26 letters of English alphabet to write down the 36 IPA sounds of English.

In this article, the author has given a clear picture of orthographic errors committed by sophomore students when they write English compositions. These orthographic errors are analysed linguistically. The errors committed by these students are slotted under different types of orthographic errors. The reasons behind the committed errors by the students and remedies are also given.

\section{Orthographic Errors}

Orthographic errors are cognitive errors consisting of the substitution of a deviant spelling for a correct one when the writer simply doesn't know the correct spelling of a particular word or forgot it or misconceived it. One can find two important characteristic features of orthographic errors.

1. They generally result in a string which is phonologically identical or very similar to the correct strings.

For example, prefre instead of prefer.

2. Proper names, infrequent words (uncommon words) and borrowed words are particularly prone to orthographic errors.

For example, datem instead of datum.

The spelling in English depends upon the phonemic/phonetic representations.

\section{Phonemic Representation}

Phonemic representation represents the sounds for linguistic studies (especially phonetics, phonology and speech processing).The linguist, A.C.Gimson created the most popular system of phonemic transcription. He used symbols from the International Phonetic Alphabet (IPA) to represent phonemes in English. 
As we see in our mother tongue, letters in English orthography represent a particular sound. For example, the word cat /kæt/ consists of three letters $c, a, t$. Where $c$ represents the sound $/ \mathrm{k} /$, a represents the sound $/ æ /$ and $t$ represents |t.

Some phonemic representations are given here:

i) Letters in multiple sequences represent as single sound.

For example, the word then is pronounced as /ðen/, where two letters $t$ and $h$ represent a single sound / $/$.

In the word bitch, the three letters $t, c$ and $h$ represent a single sound $/ t / j$.

ii) A single letter can represent multiple successive sounds. Usually the letter $x$ represents the consonant cluster /ks/. Consider the following examples:

fix - pronounced as /flks/

six - pronounced as $/ \mathrm{slks} \mid$

iii) The same letter or sequence of letters may be pronounced in different ways according to its different occurrences within a word.

For example, two letters gh represent the sound /f/ in the final position of words like rough /rAf/, tough /t/f/, etc. At the same time, the same letters gh, if they occur in the initial position of a word, then it is pronounced as $/ \mathrm{g} /$ as in ghost /goust/, ghent/gent/, ghee /gi:/, etc.

But there are exceptions such as plough and Joannesburgh for final gh which is not pronounced as /f/.

\section{Orthographic Errors Committed by College Students}

In college, most of the students who learn English as second language commit orthographic errors while they write compositions. For this study, the data were collected from sophomore English (II year) students of Eritrea Institute of Technology, Asmara from their written compositions. Samples of 2500 compositions were collected and the errors were differentiated according to the positions or environments of the phonemes. Out of these 2500 samples collected, 1554 were male students and 946 were female students. The male students committed 799 errors and female students committed 505 errors. Some errors were identical and some were different.

Usually SPELL software is used to identify the orthographic errors. The SPELL validly measures students' spelling abilities, decoding skills, and identification of sight words. It also identifies the students or individuals language impairments. Since these are not included in our study, the analysis is done manually by reading the collected compositions. After reading, the errors were identified and arranged separately and carefully without repetition.

\section{Linguistic Analysis}

Linguistics is defined as the scientific study of language. It has five main branches namely phonology, morphology, syntax, semantics and pragmatics. People who are master in linguistics and practice linguistic analysis are called linguist. The linguistic analysis refers to the scientific analysis of a collected language sample. It involves at least one of the five main branches of linguistics mentioned above. It can be used to describe the unconscious instructions and to process them. The initiative behind linguistic analysis is to understand and describe the linguistic knowledge that inspires the ability to speak a given language, and to understand how the human mind processes and creates language. In this article the linguistics analysis is used to fit the errors within the types of phonological errors.

As we have mentioned earlier, the errors committed by these students are of different types.

\section{Errors Committed through Mispronunciation}

Each and every language has its own alphabetic writing system and a correct way of writing words. In teaching and learning process, many techniques are used especially to learn the spellings. In one of such learning techniques, it is assumed that learners know how to speak the language that they must write. If the writing of a language has a one to one correspondence between phonemes and graphemes, spelling would represent a trivial task. Roy (1995) has mentioned, knowing the correct pronunciation of a word and the graphemes of an alphabet would be intuitive and easy to infer the correct spelling of any word. But sometimes in English knowing the correct pronunciation of a word does not give the writer a clue, how to spell and write it. The reason is English language has large conventional orthography. This may be the main reason for the students to commit more orthographic errors in English composition. So mispronunciation or misspellings of words in compositions are usually committed without any reason because the writer does not know the right way to pronounce or spell them. The interesting point is that such errors are particularly revealing because they are 
not committed intentionally.

Consider the following:

The word staff is pronounced as stuff and written as stuff. In the same way the following words are pronounced and written as such.

Submit as sumit

Figure as figer

Please as pleace

Surveyas survay

College as collage

College as colledge

Serious as series

Satisfy ass atisfay

However the phonological features such as addition, deletion and vowel change are found in the collected words with orthographic errors.

\subsection{Addition}

The process where there is an addition of new phoneme is called addition. In this process, the addition of phoneme doesn't change the meaning of the word.

colledge (college) - addition of $d$

satisfay (satisfy) - addition of a

peoples (people) - addition of $s$

The correct word with spelling is given in brackets.

\subsection{Deletion}

The process where sounds disappear or are not clearly articulated in certain contexts is known as deletion.

Sumit (submit) - deletion of b

Serios (serious) - deletion of $u$

Wenesday (wednesday) - deletion of $d$

Here also the meaning doesn't change even though there is deletion of a sound.

\subsection{Vowel Change}

The process of change of one vowel into another vowel is termed as vowel change. In other words, it can be said as the process of deletion and addition of vowels.

Stuff (staff) - the vowel a has changed into $u$

Collage (college) - the vowel e has changed into a

\section{Errors Committed through Uncommon Words}

Orthographic errors are also committed because of uncommon words used in spoken referents. English language has rich written uses, technical words and borrowed words used in writing but seldom in spoken. In such cases, errors are possible from simple ignorance of the exact spelling of words without implications regarding the relation between sounds and letters.

Prompts is written as proms

Distortion is written as distosion

\section{Errors Committed through Borrowed Words}

Another type of spelling characteristic is related to the word origin. Since many words in English are borrowed from other languages like Greek, Latin, German, French, Tamil, etc. there are more possibilities for a non-native student to commit errors.

datum is written as datem 
criterion is written as criterian

myth is written as mith

\section{Positions of Phoneme}

Linguistically speaking, there are three occurrences or positions for a single phoneme in a word. They are initial, medial and final. The errors committed by the students can be differentiated according to its positions.

\subsection{Initial}

The orthographic errors committed at the initial position of a word.

Thing is written as sing (no change in meaning)

Busy is written as vusy

\subsection{Medial}

Errors committed at the medial position of a word.

Disturb is written as disterb

Submit is written as sumit

Width is written as with

\subsection{Final}

The orthographic errors committed at the final position of a word.

Month is written as monthe

Child is written as childe

Conclude is written as conclud

Please is written as pleas

Telephone is written as telephon

The statistical analysis says that $70 \%$ of the errors are committed at the word final position, $28 \%$ at medial position and remaining at the initial position.

\section{Conclusion}

Errors are not a homogenous set. Some types of errors are linked to limitations in the writer's stylistic choices or time constraints on composition and so on.

Sometimes analyzing and understanding the orthographic errors may lead the students to be aware of orthographic errors.

Now-a-days most of the students use computers, laptops, notepads and tablets for different purposes, but the basic need of these is to 'type'. This may also lead the students to commit errors. Because, if a student types a word with erroneous spelling, the system itself corrects it automatically, due to the default spell checker loaded in the system. So the student, when he/she writes has the tendency of committing the spelling errors.

Orthographic errors are probably caused by mishearing also. When the students watch English movies or listen English news, they mishear many words like, Wednesday as wenesday, college as collage, Literature as litrature, thing as sing, etc.

So, derivational morphology, origin of words, borrowed words, coinage of words, spelling rules can be taught when the students are in Freshman (I year) or in Matriculation (school).

\section{Acknowledgement}

My sincere gratitude to my colleagues and my students who helped me in collecting data and analysing them. Also my gratitude to my authorities who supported me. 


\section{References}

Bell, Masha. (2009). Rules and Exceptions of English Spelling. Cambridge: Pegasus.

Boron, Naomi. S. (2000). Alphabet to e-mail. London: Routledge.

Chomsky Noam. (1980). Rules and Representations. New York: Columbia University Press.

Crystal, David. (2006). Language and Internet. Cambridge: Cambridge University Press.

Frisch S. (2000). Temporally organized Lexical Representations as Phonological Units. In: Broe MB, Pierrehumbert JB, (eds). Papers in Laboratory phonology V: Acquisition and the Lexicon. Cambridge: Cambridge University Press. pp. 283-298.

Frisch SA, Wright R. (2002). The Phonetics of Phonological Speech Errors: An Acoustic Analysis of Slips of the Tongue. Journal of Phonetics. Vol.30: pp.139-162.

Gimson, A.C. (1967). English Pronouncing Dictionary. London: Edward Arnold.

Gimson, A.C. (1980). An Introduction to the Pronunciation of English. London: Edward Arnold.

Goldrick M. (2004). Phonological features and Phonotactic Constraints in Speech Production. Journal of Memory and Language.51: pp. $586-603$.

Greenberg JH. (1966). Language Universals. Mouton: The Hague.

Hudson, Richard. (1990). English Word Grammar. Oxford: Blackwell.

Kupin JJ. (1982). Tongue Twisters as a Source of Information about Speech Production. Bloomington: Indiana University Linguistics Club.

Maddieson I. (1984). Patterns of Sounds. Cambridge: Cambridge University Press.

Roy, H. (1995). Signs of Writing. London: Routledge.

Sampson, Geoffrey. (1985). Writing Systems: A Linguistic Introduction. London: Hutchinson.

Stemberger JP. (1983). Speech Errors and Theoretical Phonology: A Review. Bloomington: Indiana University Linguistics Club.

Thambi Jose, Franklin. (2007). Orthographic Errors committed by Assamese Speakers while they learn Tamil as Second Language. Paper presented in the Seminar on Language Teaching. Pune: Western Regional Language Center. (unpublished paper) Venezky R.L. (1970). The Structure of English Orthography.Mouton: The Hague.

Vijaya, P. (2001). Error Analysis. Ph.D. Dissertation, CAS in Linguistics, Annamalai University. (unpublished) www.wisegeek.com 